\title{
Article \\ Sensing, Actuation, and Control of the SmartX Prototype Morphing Wing in the Wind Tunnel
}

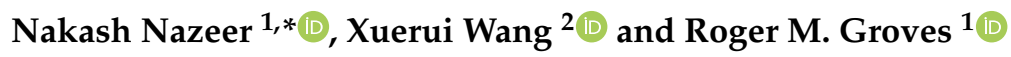 \\ 1 Aerospace NDT Laboratory, Faculty of Aerospace Engineering, Delft University of Technology, \\ Kluyverweg 1, 2629 HS Delft, The Netherlands; R.M.Groves@tudelft.nl \\ 2 Section of Aerospace Structures and Computational Mechanics \& Section of Control and Simulation, \\ Faculty of Aerospace Engineering, Delft University of Technology, Kluyverweg 1, \\ 2629 HS Delft, The Netherlands; X.Wang-6@tudelft.nl \\ * Correspondence: N.Nazeer@tudelft.nl
}

Citation: Nazeer, N.; Wang, X.;

Groves, R.M. Sensing, Actuation, and Control of the SmartX Prototype Morphing Wing in the Wind Tunnel. Actuators 2021, 10, 107. https://doi. org/10.3390/act10060107

Academic Editor: Ronald M. Barrett

Received: 2 April 2021

Accepted: 18 May 2021

Published: 21 May 2021

Publisher's Note: MDPI stays neutral with regard to jurisdictional claims in published maps and institutional affiliations.

Copyright: (c) 2021 by the authors. Licensee MDPI, Basel, Switzerland. This article is an open access article distributed under the terms and conditions of the Creative Commons Attribution (CC BY) license (https:/ / creativecommons.org/licenses/by/ $4.0 /)$.

\begin{abstract}
This paper presents a study on trailing edge deflection estimation for the SmartX camber morphing wing demonstrator. This demonstrator integrates the technologies of smart sensing, smart actuation and smart controls using a six module distributed morphing concept. The morphing sequence is brought about by two actuators present at both ends of each of the morphing modules. The deflection estimation is carried out by interrogating optical fibers that are bonded on to the wing's inner surface. A novel application is demonstrated using this method that utilizes the least amount of sensors for load monitoring purposes. The fiber optic sensor data is used to measure the deflections of the modules in the wind tunnel using a multi-modal fiber optic sensing approach and is compared to the deflections estimated by the actuators. Each module is probed by single-mode optical fibers that contain just four grating sensors and consider both bending and torsional deformations. The fiber optic method in this work combines the principles of hybrid interferometry and FBG spectral sensing. The analysis involves an initial calibration procedure outside the wind tunnel followed by experimental testing in the wind tunnel. This method is shown to experimentally achieve an accuracy of $2.8 \mathrm{~mm}$ deflection with an error of $9 \%$. The error sources, including actuator dynamics, random errors, and nonlinear mechanical backlash, are identified and discussed.
\end{abstract}

Keywords: structural health monitoring; optical fiber sensing; multi-modal sensing; morphing wing; fiber bragg grating; FBG pair; shape sensing; wind tunnel; servos; actuators

\section{Introduction}

An engineering structure is normally expected to function within its design limits throughout its service life. Structural Health Monitoring (SHM) [1] has been the go-to approach to oversee the structural integrity of many engineering structures. SHM consists of 5 levels [2], viz., (1) Detection, (2) Localization, (3) Classification, (4) Assessment, and (5) Prediction. This work specifically pertains to level one of SHM: Load monitoring, which concerns itself with the detection of the presence or the indication of structural changes due to external factors. SHM has been used in different fields, including those in aerospace [3-6], wind turbine-blades [7], pipeline [8], and civil engineering [9].

In particular, aircraft wings are prone to high bending and torsional deformations during their flight regime. Wing shape-changes also alter the aerodynamics and are a source of load acting on the wing [10]. Monitoring these loads in real-time is crucial to make sure the wing is operating within its design limits, and this is considered as the first level of SHM [11]. Research on aircraft designs have steered towards morphing wings [10] in recent years and have become quite popular.

Morphing, indicating the ability to transform shape, has great potential for reducing aircraft drag and fuel consumption [12]. Researchers from Delft University of Technology 
have designed, manufactured, and tested a seamless active morphing wing named SmartXAlpha [13]. This wing utilizes the translation induced camber (TRIC) mechanism to induce camber morphing [13]. There are six independent morphing modules along the wing span of SmartX-Alpha, and each of them is actuated by two independent servos. The six morphing modules are connected by elastomer materials for smooth transitions. This smooth active morphing design allows the wing to adapt its shape to various flight conditions and to maximize its aerodynamic efficiency in real-time. Furthermore, active seamless morphing surfaces can avoid the gaps induced by conventional discrete wing trailing-edge control surfaces, leading to reductions in drag and noise.

Aircraft structural loads can be amplified significantly during sharp maneuvers, which can lead to structural fatigue and even local structural damage. Therefore, it is crucial to alleviate aircraft structural loads during maneuvers [14]. In the literature, a wide variety of control methods have been implemented for aircraft maneuver load alleviation (MLA) purposes, e.g., linear quadratic Gaussian (LQG) [15], linear model predictive control (MPC) [16], linear proportional-integral-derivative (PID) control [17], etc. However, since the aircraft operational conditions can change dramatically throughout its flight envelope, these linear control methods have to be used along with the tedious gain-scheduling approach [18]. By contrast, nonlinear control methods such as feedback linearization and backstepping can directly consider the operational condition variations. Different from the mainstream model-based nonlinear control methods, the novel incremental nonlinear dynamic inversion (INDI) control is sensor-based [19]. By exploiting sensor measurements, INDI simultaneously reduces its model dependency and enhances its robustness against model uncertainties and external disturbances [19]. These features make it promising for aircraft load alleviation problems [20]. In this paper, the MLA control law is executed by six distributed wing trailing-edge morphing surfaces. To accurately know the morphing control effectiveness, it is important to sense the morphing surface deformations in real-time.

Optical fibers (sensors) are remarkably suited to fulfil the requirements for aerospace applications [21]. They have advantages, including high sensitivity, accuracy, multiplexing capabilities, and the possibility of being inconspicuously embedded in structures [22,23]. Needless to say, they have attracted a lot of attention and are the preferred technology for shape sensing [24] and wing deformation monitoring [25,26]. Fiber Bragg grating (FBG)based optical fiber sensors are predominantly used and, depending on their application, can either be single point [27] or quasi-distributed FBG sensors [28]. In this work, we use a quasi-distributed FBG sensor layout.

The main contribution of this study is the integration of sensing, actuation, and control of camber-morphing wing modules. This has been done by estimating the deflections of the modules using a single-core optical fiber sensor followed by evaluating the actuator effectiveness during morphing. Furthermore, an attempt is made to reduce the dependency on using a high amount of sensors to achieve this. The focus is also on developing a method that does not involve complex manufacturing methods, for example, multi-core fibers with gratings inscribed in each core [29-31], and at the same time is not dependent on large sensor arrays [28,32]. The method proposed demonstrates the functionality of a novel way of interpreting optical fiber strain data which, apart from measuring local strain, deals with measuring the change in optical pathlength between sensors [33].

This paper is organized into seven sections. A brief introduction of the focus of this study, the technologies used and state of the art are summarized in Section 1. Section 2 introduces the optical sensing principles, the proposed hybrid optical sensing approach and the morphing control design. Section 3 covers the experimental work, including the setup, the morphing module, and the fiber layout. Section 4 explains the measurement procedure and process from calibration, as well as algorithms to the experiment campaign involving Maneuver Load Alleviation tests. Section 5 presents a compilation of all the outcomes of the experiments, whilst Section 6 reviews and discusses all those findings. Finally, the conclusions reached and recommendations for future work are summarized in Section 7. 


\section{Theory}

In this work, incremental nonlinear dynamic inversion with quadratic programming control allocation and virtual shape functions (INDI-QP-V) is used to monitor the actuator deflections and achieve the desired actuator control. Furthermore, fiber Bragg grating (FBG) sensors are used for deflection monitoring of the morphing modules. As each grating sensor gives one output reading, we also read data between two gratings, considering them as sensor pairs, to increase the number of measurement data acquired [33].

The basic concepts and principles of the shape assessment logic and the morphing control logic are as follows.

\subsection{Shape Assessment Logic}

The hybrid approach for optical fiber sensing and shape assessment presented in this work transpires from the combination of spectral sensing (Section 2.1.1) for local sensor measurement and interferometric sensing (Section 2.1.2) for measuring between sensor pairs.

\subsubsection{FBG Spectral Sensing}

The structure of a typical optical fiber containing a Bragg grating is as shown in Figure 1. The core of the optical fiber contains a grating of length $L_{F B G}$ and period $\Lambda$. The gratings couple a narrow spectral band of light from the forward-propagating mode to the counter propagating mode [34]. A laser, with the help of a phase mask is used to etch the required spatial pattern in the fiber core. These gratings are basically changes in the RI of the core due to exposure to laser light. Therefore, in order to easily achieve this, photosensitive fibers are normally used [35].

This length $\left(L_{F B G}\right)$ of the fiber is what forms the effective sensing length. At the Bragg wavelength [36], this region acts as a bandpass and bandstop filter in transmission and reflection, respectively. The Bragg wavelength is given by

$$
\lambda_{B}=2 n_{e f f} \Lambda,
$$

where $n_{\text {eff }}$ is the effective refractive (RI) index of the fiber core, and $\Lambda$ is the periodic spacing of the grating. All FBGs work on this 'Bragg reflection' principle [21].

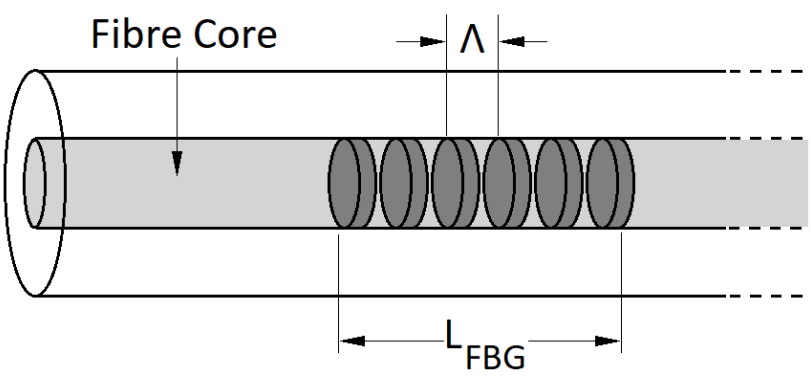

Figure 1. Typical fiber Bragg grating (FBG) sensor containing gratings in its core. $L_{F B G}$ is the length of the grating, and $\Lambda$ is the grating period.

The length and periodic spacing of the gratings are varied as per their applications. The gratings typically are between $1 \mathrm{~mm}$ to $20 \mathrm{~mm}$ [37] in length and have a sub-micron periodic spacing.

External Mechanical and/or thermal changes on the fiber influence the Bragg wavelength $\lambda_{B}$ (from Equation (1)) as it is dependent on changes in the RI and periodic spacing of the grating. This shift in wavelength is indicated by $\Delta \lambda_{B}$ and can be represented as a change in the calculated strain $\Delta \varepsilon$ as [38]:

$$
\Delta \varepsilon=\frac{\Delta \lambda_{B}}{\lambda_{B}\left(1-\rho_{a}\right)}-\Delta T\left(\alpha_{n}+\frac{\xi}{\left(1-\rho_{a}\right)}\right),
$$


where $\rho_{a}$ is the photoelastic coefficient, $\alpha$ is the thermal expansion coefficient, $\xi$ is the thermo-optic coefficient, and $\Delta T$ the change in ambient temperature.

In order to read and understand this wavelength shift, a second reference Bragg wavelength is required. This is recorded at a reference loading state of the structure. Spectrometers, contained in FBG interrogator systems are used to record the reflection spectra, and the central Bragg wavelength is determined by calculation. Finally, the measured wavelength shift is converted to a value in terms of strain. Strain values are typically expressed in micro-strains $(\mu \varepsilon)$.

Figure 2 shows an example spectra of an FBG when strained and unstrained. In this example, the shift in the Bragg wavelength is depicted due to the applied strain.

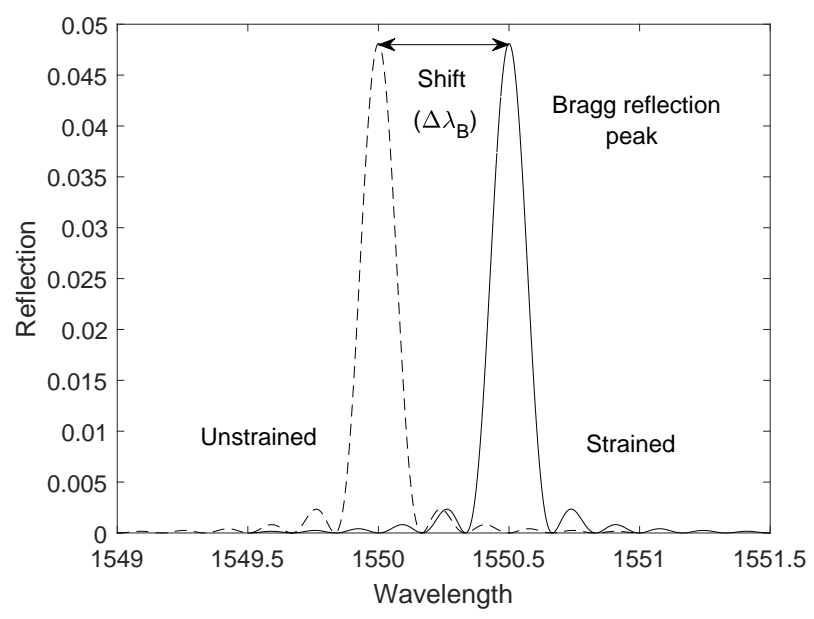

Figure 2. Example spectra of the FBG, indicating the shift in Bragg reflection peak due to the fiber undergoing tension.

\subsubsection{FBG Pair Interferometric Sensing}

The fundamental structure of a typical sensor pair is as shown in Figure 3. The sensing approach is based on the principle of comparing phase differences between interference patterns [39] within a cavity. This cavity or region is formed between two parallel partially reflecting mirrors marked as $R_{1}$ and $R_{2}$. The length between these two reflectors is what forms the active (sensing) region and is denoted by its length $L_{A R}$.

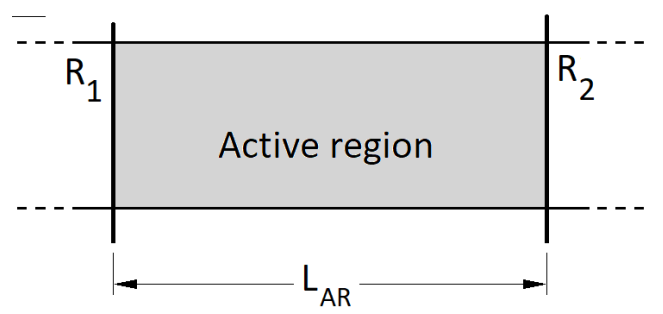

Figure 3. Typical sensor pair containing two partially reflecting mirrors $R_{1}$ and $R_{2}$. $L_{A R}$ is the length of the active region or FBGP cavity.

Active regions can be the optically transparent medium within optical fibers. The active region (or cavity) and the reflecting mirrors, in this case, are within the fiber core and can be the FBG's shown in Figure 1. This configuration, as well as for the purpose of our work, is referred to as FBG pairs or FBGP. The fiber that contains the active region is referred hereon as the sensing fiber.

A second reference fiber is used that reflects light off of a mirror which is then compared to the reflected lights from each of the gratings in the sensing fiber. The FBGP cavity is sensitive to the changes in wavelength and/or the spacing between the reflectors. Reflected light from the reference and sensing fiber are combined to form an interference 
pattern which further gives information on their phase differences. This phase difference is a function of the length $L$ between the two grating sensors (where $L=L_{A R}$ ) and gives information on the change in optical pathlength between them. This displacement $(\Delta L)$ is calculated as:

$$
\Delta L=\frac{1}{n}\left[\left(\frac{\Delta \Phi \lambda}{2 \pi}\right)-L \Delta n\right]
$$

where $n$ is the refractive index, $\Phi$ is the phase difference, and $\lambda$ is the wavelength at which the grating reflects light.

Similar to the FBGs, external mechanical and/or thermal changes influence the cavity length $L_{A R}$, and the calculated strain $(\varepsilon)$ can be expressed as:

$$
\frac{\Delta L-L_{t} \Delta T}{L_{A R}}
$$

where $\Delta T$ is the change in ambient temperature, and $L_{t}$ is the change in cavity length due to this change in temperature. In this study, temperature changes are considered to be negligible.

Figure 4 shows an example spectra of the FBGP when strained and unstrained. In this example, three stages are depicted. A gradual strain is applied on the fiber, followed by a brief hold and ending with releasing the applied strain. These stages happen within a period of $\sim 1$ s each.

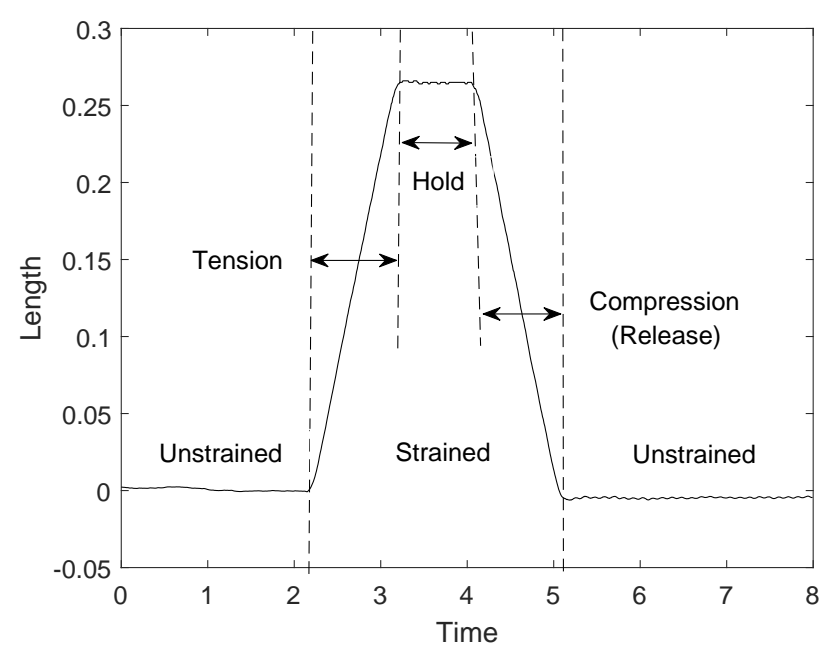

Figure 4. Example spectra of the FBG pair, indicating the sensing fiber undergoing gradual tension and compression.

\subsubsection{Multi-Modal Sensing Principle}

The multi-modal sensing approach follows a two step FBG measurement procedure which combines FBG spectral sensing (Section 2.1.1) and FBGP interferometry (Section 2.1.2). The authors have previously reported this sensing approach for the purpose of estimating loading position and magnitude on a cantilever plate [33] imitating a wing section. In this study, this model is used to demonstrate the feasibility of measuring the tip deflections of a morphing wing section in the wind tunnel.

The measurement procedure requires data acquisition from both sensing methods. The local strain from the FBGs is calculated by taking into account the spectral shift of each of the gratings using Equation (2). The other measurement step, interferometric sensing, requires grating pairs. This is because the gratings, in this case, act as the partial reflectors $R_{1}$ and $R_{2}$, as shown in Figure 3. The displacement in terms of strain is then calculated by measuring the change in optical distance between any two given gratings. The minimum number of gratings required for a single axis pure-bend sensing using this multi-modal sensing approach is 2 [40]. For structures with widths of comparable dimensions with their 
lengths (example: cantilever plates [33]), torsion also plays a role. Hence, multiple grating pairs are incorporated in the morphing wing. Each of the FBGs are identified by their respective central wavelengths. The Wavelength Division Multiplexing (WDM) scheme is used to tell each grating apart.

Lastly, the algorithm (described in-depth in Section 4) makes use of the measured local FBG strain data, as well as the displacement between each of the FBGs for the estimation. This gives two sets of measurements: (1) $\varepsilon_{1}, \varepsilon_{2}, \varepsilon_{3}$, and $\varepsilon_{4}$ local strain measurements from the $F B G$ readings; (2) $\triangle L_{1-2}$ and $\triangle L_{3-4} F B G P$ readings from the interferometric measurements. A Camber Morphing $\rightarrow$ Optical Fiber Strain $\rightarrow$ Trailing-edge Displacement transfer function is used to relate the measurement data to the tip deflection of the morphing module. In order to identify and isolate twist in the camber, separate transfer functions are used that correspond to each of the actuators that control the morphing sequences.

\subsection{Morphing Control Logic}

The active morphing function of the SmartX-Alpha enables it to achieve control objectives in a seamless way. To guarantee the aerodynamic effectiveness of the morphing surfaces, it is very important to monitor and know the actual morphed shape and deformations of the control modules. The multi-modal fiber optic sensing approach is prefect to achieve this goal because of its capability of monitoring bending and torsional deformations, whilst, at the same time, using least number of sensors. The shape sensing and morphing control method used compliment each other to achieve one of the objectives for the SmartX-Alpha wing, which is to simultaneously alleviate gust and maneuver loads. In this paper, the incremental nonlinear dynamic inversion with quadratic programming control allocation and virtual shape functions (INDI-QP-V) is proposed to reach this objective [41].

\subsubsection{Incremental Control Theory}

The morphing wing under the perturbation of disturbances is modeled as [41]:

$$
\dot{x}=f(x)+G(x) u+d(t), \quad y=h(x),
$$

where $x$ and $y$ are the state and output vectors, respectively. $u$ is the control input vector. $f: \mathbb{R}^{n} \rightarrow \mathbb{R}^{n}$ and $\boldsymbol{h}: \mathbb{R}^{n} \rightarrow \mathbb{R}^{p}$ are smooth vector fields; $G$ is a smooth function mapping $\mathbb{R}^{n} \rightarrow \mathbb{R}^{n \times m}$, in which its columns are smooth vector fields, and $\boldsymbol{d}(t) \in \mathbb{R}^{n}$ represents the external disturbance vector. Assume that $\|\boldsymbol{d}(t)\|_{2} \leq \bar{d} . y \in \mathbb{R}^{p}$ in Equation (5) denotes the controlled output vector, which can be a function of any subset of the physical measurable outputs. Consider the case where $p<m$, which leads to an over-actuated control problem. Referring to the Frobenius theorem [42], there exist smooth functions $\phi(x)=\left[\phi_{1}(x), \ldots, \phi_{n-\rho}(x)\right]^{\top}$ defined in a neighborhood of the equilibrium point, such as Equation (5), can be transformed into:

$$
\begin{aligned}
\dot{\eta} & =f_{\eta}(\boldsymbol{\eta}, \boldsymbol{\xi}, \boldsymbol{d})=\left.\frac{\partial \phi}{\partial x}(f(x)+\boldsymbol{d}(t))\right|_{x=T^{-1}(z)} \\
\dot{\boldsymbol{\xi}} & =A_{c} \xi+\boldsymbol{B}_{c}\left[\boldsymbol{\alpha}(\boldsymbol{x})+\mathcal{B}(x) \boldsymbol{u}+\boldsymbol{d}_{y}\right] \\
y & =\boldsymbol{C}_{c} \boldsymbol{\xi}
\end{aligned}
$$

where $\boldsymbol{A}_{c}=\operatorname{diag}\left\{\boldsymbol{A}_{*}^{i}\right\}, \boldsymbol{B}_{c}=\operatorname{diag}\left\{\boldsymbol{B}_{*}^{i}\right\}, \boldsymbol{C}_{c}=\operatorname{diag}\left\{\boldsymbol{C}_{*}^{i}\right\}, i=1,2, \ldots, p$, and $\left(\boldsymbol{A}_{*}^{i}, \boldsymbol{B}_{*}^{i}, \boldsymbol{C}_{*}^{i}\right)$ is a canonical form representation of a chain of $\rho_{i}$ integrators. $\boldsymbol{\alpha}(\boldsymbol{x}), \boldsymbol{B}(\boldsymbol{x})$, and $\boldsymbol{d}_{y}$ formulate the transformed input-output mapping by considering the system relative degree $\rho=\left[\rho_{1}, \rho_{2}, \ldots, \rho_{p}\right]^{\top}[43]$. In Equation (6), $z=\boldsymbol{T}(\boldsymbol{x})=\left[\boldsymbol{\eta}^{\top}, \xi^{\top}\right]^{\top}$, where $\boldsymbol{\eta}$ and $\boldsymbol{\xi}$ represent the internal and external state vectors, respectively.

Instead of designing the entire control input $u$, the incremental nonlinear dynamic inversion (INDI) control designs the control increment in one sampling interval $\Delta t$. Taking 
the first-order Taylor series expansion of the output dynamics around the condition at $t-\Delta t$ (denoted by the subscript 0 ) as

$$
\begin{aligned}
y^{(\rho)} & =\alpha(x)+\mathcal{B}(x) \boldsymbol{u}+\boldsymbol{d}_{y} \\
& =y_{0}^{(\rho)}+\left.\frac{\partial[\boldsymbol{\alpha}(\boldsymbol{x})+\mathcal{B}(x) \boldsymbol{u}]}{\partial x}\right|_{0} \Delta x+\mathcal{B}\left(x_{0}\right) \Delta u+\Delta \boldsymbol{d}_{y}+\boldsymbol{R}_{1}
\end{aligned}
$$

where $\Delta x, \Delta u$, and $\Delta d_{y}$, respectively, represents the state, control, and disturbance increments in one sampling time step $\Delta t$. In Equation (7), $\boldsymbol{R}_{1}$ is the expansion remainder.

Define the output reference signal as $\boldsymbol{y}_{r}(t)=\left[y_{r_{1}}(t), y_{r_{2}}(t), \ldots, y_{r_{p}}(t)\right]^{\top}$. The resulting tracking error vector equals $e=\xi-\mathcal{R}$, where $\mathcal{R}=\left[\mathcal{R}_{1}^{\top}, \mathcal{R}_{2}^{\top}, \ldots, \mathcal{R}_{p}^{\top}\right]^{\top}, \mathcal{R}_{i}=$ $\left[y_{r_{i}}, y_{r_{i}}^{(1)}, \ldots, y_{r_{i}}^{\left(\rho_{i}-1\right)}\right]^{\top}, i=1,2, \ldots, p$. The references are designed to be bounded signals; thus, $\|\mathcal{R}\|_{2} \leq \overline{\mathcal{R}}$. To stabilize the error dynamics, design the INDI control increment to satisfy the following equation:

$$
\overline{\mathcal{B}}\left(x_{0}\right) \Delta u_{\text {indi }}=v_{c}-y_{0}^{(\rho)}, \quad v_{c}=y_{r}^{(\rho)}-K e,
$$

where the gain matrix $\boldsymbol{K}=\operatorname{diag}\left\{\boldsymbol{K}_{i}\right\}, i=1,2, \ldots, p$, and $\boldsymbol{K}_{i}=\left[K_{i, 0}, K_{i, 1}, \ldots, K_{i, \rho_{i}-1}\right]$ is designed such that $\boldsymbol{A}_{c}-\boldsymbol{B}_{c} \boldsymbol{K}$ is Hurwitz. $\overline{\mathcal{B}}\left(\boldsymbol{x}_{0}\right)$ in Equation (8) is the estimated control effectiveness matrix. When Equation (8) is satisfied, the closed-loop system dynamics are:

$$
\begin{aligned}
\dot{\eta} & =f_{\eta}(\boldsymbol{\eta}, \boldsymbol{\xi}, \boldsymbol{d})=\left.\frac{\partial \boldsymbol{\phi}}{\partial x}(\boldsymbol{f}(\boldsymbol{x})+\boldsymbol{d}(t))\right|_{x=T^{-1}(z)} \\
\dot{\boldsymbol{e}} & =\left(\boldsymbol{A}_{c}-\boldsymbol{B}_{c} \boldsymbol{K}\right) \boldsymbol{e}+\boldsymbol{B}_{c}\left[\delta(x, \Delta t)+\left(\mathcal{B}\left(x_{0}\right)-\overline{\mathcal{B}}\left(x_{0}\right)\right) \Delta \boldsymbol{u}_{\mathrm{indi}}+\varepsilon_{\mathrm{ca}}+\Delta \boldsymbol{d}_{y}\right] \\
& \triangleq\left(A_{c}-\boldsymbol{B}_{c} \boldsymbol{K}\right) \boldsymbol{e}+\boldsymbol{B}_{c} \varepsilon_{\text {indi }}
\end{aligned}
$$

where $\delta(x, \Delta t)$ is the closed-loop value of the expansion reminder and variations. $\varepsilon_{\mathrm{ca}}$ in Equation (10) is the possible control allocation error.

Theorem 1 (Reference [41]). If $\left\|\varepsilon_{\text {indi }}\right\|_{2} \leq \bar{\varepsilon}$ is satisfied for all $\xi \in \mathbb{R}^{\rho}, f_{\eta}(\boldsymbol{\eta}, \boldsymbol{\xi}, \boldsymbol{d})$ is continuously differentiable and globally Lipschitz in $(\boldsymbol{\eta}, \boldsymbol{\xi}, \boldsymbol{d})$, and the origin of $\dot{\eta}=f_{\eta}(\boldsymbol{\eta}, \mathbf{0}, \mathbf{0})$ is globally exponentially stable, then the tracking error $\boldsymbol{e}$ in Equation (10) is globally ultimately bounded by a class $\mathcal{K}$ function of $\bar{\varepsilon}$, whilst the internal state $\boldsymbol{\eta}$ in Equation (10) is globally ultimately bounded by a class $\mathcal{K}$ function of $\bar{\varepsilon}, \overline{\mathcal{R}}$, and $\bar{d}$.

Different from the widely used model-based feedback linearization method, the INDI method is sensor-based. The only model information needed by INDI is the control effectiveness estimation $\overline{\mathcal{B}}\left(x_{0}\right)$. This significantly simplifies its identification and implementation processes. Even though its model dependency is reduced, by exploiting the sensor measurements, INDI actually has better robustness against uncertainties and disturbances than feedback linearization [19].

\subsubsection{Control Allocation with Virtual Shape Functions}

In Equation (8), $\overline{\mathcal{B}}\left(x_{0}\right) \in \mathbb{R}^{p \times m}$. When the roll rank of $\overline{\mathcal{B}}$ equals $p$, whilst the column rank of $\overline{\mathcal{B}}$ is larger than $p$, then there are infinite solutions to satisfy Equation (8). This paper aims at finding the control increment from Equation (8), whilst meeting the input constraints and ensuring the smoothness of the morphing wing.

The input constraints include servo position and rate constraints. For this morphing wing, the adjacent morphing modules are connected by elastomer materials. In order to avoid over-stretching the elastomer, the relative rotations between the adjacent servos should also be constrained. Using the boolean selection matrices, the servo position, rate, and relative position constraints can be integrated into an inequality denoted as $\boldsymbol{A}_{u} \Delta \boldsymbol{u} \leq \boldsymbol{b}_{u}[41]$. 
To ensure the spanwise smoothness of the morphing wing at every time step, virtual shape functions are introduced. It is worth noting that the virtual shape functions are different from the structural mode shapes; instead, they are only introduced as a transformation in control design aiming for smooth spanwise transitions. Consider a morphing wing in which its half wing span equals $L$, as well as has $m$ distributed servos with normalized spanwise location $\bar{x}_{s}=\left[x_{s, 1} / L, x_{s, 2} / L, \ldots, x_{s, m} / L\right]^{\top}$. Design the virtual shape matrix as:

$$
\boldsymbol{\Phi}_{\bar{x}_{s}}=\left[\begin{array}{cccc}
T_{0}\left(\bar{x}_{s, 1}\right) & T_{1}\left(\bar{x}_{s, 1}\right) & \ldots & T_{q}\left(\bar{x}_{s, 1}\right) \\
T_{0}\left(\bar{x}_{s, 2}\right) & T_{1}\left(\bar{x}_{s, 2}\right) & \ldots & T_{q}\left(\bar{x}_{s, 2}\right) \\
\vdots & \vdots & & \vdots \\
T_{0}\left(\bar{x}_{s, m}\right) & T_{1}\left(\bar{x}_{s, m}\right) & \ldots & T_{q}\left(\bar{x}_{s, m}\right)
\end{array}\right],
$$

where $T_{i}$ is the Chebyshev polynomial of the first kind:

$$
T_{1}\left(\bar{x}_{s}\right)=1, T_{2}\left(\bar{x}_{s}\right)=\bar{x}_{s}, T_{i+1}=2 \bar{x}_{s} T_{i}\left(\bar{x}_{s}\right)-T_{i-1}\left(\bar{x}_{s}\right), i=2,3, \ldots, q-1 .
$$

Use $\boldsymbol{\Phi}_{\bar{x}_{s}} \in \mathbb{R}^{m \times q}$ as a smooth mapping between the real control increment $\Delta \boldsymbol{u} \in \mathbf{R}^{m}$ and a new control variable $\Delta \boldsymbol{u}_{v} \in \mathbf{R}^{q}$, i.e., $\Delta \boldsymbol{u}=\boldsymbol{\Phi}_{\bar{x}_{s}} \Delta \boldsymbol{u}_{v}$. Consequently, for any $\Delta \boldsymbol{u}_{v} \in \mathbf{R}^{q}$, the resulting $\Delta \boldsymbol{u}$ ensures the $q$-th order smoothness of the wing trailing-edge shape in the spanwise direction [41]. Denote the servo setting for realizing the nominal wing shape as $\boldsymbol{u}_{*}$, then the control allocation with virtual shape functions can be reformulated into a quadratic programming problem as [41]:

$$
\begin{aligned}
\min _{\Delta \boldsymbol{u}_{v}} \mathcal{J}_{1}= & \frac{1}{2} \Delta \boldsymbol{u}_{v}^{\top}\left(\boldsymbol{\Phi}_{\bar{\chi}_{s}}^{\top} \overline{\mathcal{B}}^{\top}\left(\boldsymbol{x}_{0}\right) \boldsymbol{W}_{1} \overline{\mathcal{B}}\left(\boldsymbol{x}_{0}\right) \boldsymbol{\Phi}_{\bar{x}_{s}}+\sigma \boldsymbol{\Phi}_{\bar{x}_{s}}^{\top} \boldsymbol{W}_{2} \boldsymbol{\Phi}_{\bar{x}_{s}}\right) \Delta \boldsymbol{u}_{v} \\
& +\left(\left(\boldsymbol{y}_{0}^{(\rho)}-\boldsymbol{v}_{c}\right)^{\top} \boldsymbol{W}_{1} \overline{\mathcal{B}}\left(\boldsymbol{x}_{0}\right)+\left(\boldsymbol{u}_{0}-\boldsymbol{u}_{*}\right)^{\top} \sigma \boldsymbol{W}_{2}\right) \boldsymbol{\Phi}_{\bar{x}_{s}} \Delta \boldsymbol{u}_{v}, \\
\text { subject to } \quad & \left(\boldsymbol{A}_{u} \boldsymbol{\Phi}_{\bar{x}_{s}}\right) \Delta \boldsymbol{u}_{v} \leq \boldsymbol{b}_{u},
\end{aligned}
$$

where $\boldsymbol{W}_{1}$ and $\boldsymbol{W}_{2}$ are weighting matrices. $\sigma$ in Equation (13) represents the weight between realizing Equation (8) and minimizing the control energy.

The features of this formulation include: (1) the servo position, rate, and relative position constraints are explicitly considered; (2) the wing trailing-edge smoothness is guaranteed at every time step; (3) the computation load is reduced because the only model information needed by Equation (13) is the control effectiveness matrix. In addition, the optimization searching degrees of freedom are reduced from $m$ to the user-defined $q$.

The solution of Equation (13) is literally the control increment of INDI-QP-V. The actual command vector to the servos equals $\boldsymbol{u}_{\text {cmd }}=\boldsymbol{\Phi}_{\bar{x}_{s}} \Delta \boldsymbol{u}_{v}+\boldsymbol{u}_{0}$. Assume the relationship between the real control effectiveness and its estimation yields $\mathcal{B}\left(x_{0}\right)=\boldsymbol{K}_{\mathcal{B}}\left(\boldsymbol{x}_{0}\right) \overline{\mathcal{B}}\left(x_{0}\right)$, and then the following Corollary holds true:

Corollary 1 (Reference [41]). When the quadratic programming control allocation with virtual shape functions is used (Equation (13)), if $\left\|\boldsymbol{I}-\boldsymbol{K}_{\mathcal{B}}\left(\boldsymbol{x}_{0}\right)\right\|_{2} \leq \bar{b}^{\prime}<1$, and if $\delta(\boldsymbol{x}, \Delta t), \Delta \boldsymbol{d}_{y}$, and $\boldsymbol{\varepsilon}_{c a}$ are, respectively, bounded by $\bar{\delta}, \overline{\Delta d}$, and $\bar{\varepsilon}_{c a}$, then, under sufficiently high sampling frequency, $\varepsilon_{\text {indi }}$ in Equation (10) is ultimately bounded.

\subsubsection{Maneuver Load Alleviation}

In Sections 2.2.1 and 2.2.2, the INDI-QP-V control has been derived for generic nonlinear system output tracking problem. In this subsection, INDI-QP-V will be used for alleviating aircraft wing maneuver loads. The wing root shear force $F_{y}$ and bending moment $M_{x}$ are two important load indicators (plotted in Figure 5). Their values can be measured by an external balance in real-time. Choose $y=\left[\int F_{y}, \int M_{x}\right]^{\top}$ for load alleviation purposes. The system input $u$ are the twelve distributed servos. As a consequence, the system input-output relative degree vector is $\rho=[1,1]^{\top}$. 
The wing load alleviation is achieved by tracking the load references using INDI-QP-V. For example, in a symmetrical pull-up maneuver, the wing root shear force $F_{y}$ should be increased to amplify the load factor. If the maneuver load alleviation is not performed, then the wing root bending moment $M_{x}$ would also been amplified. By contrast, the spanwise lift distribution can be modified by the trailing-edge control surfaces, which makes it possible to increase the total lift without amplifying the bending loads. To be specific, in a symmetrical pull-up maneuver case, the outboard surfaces should morph up to reduce lift, whilst the inboard surfaces should morph down to increase lift. As a result, the wing aerodynamic center is shifted inboard for alleviating maneuver loads. The spanwise lift-redistribution can also be used for alleviating wing loads during sharp roll.

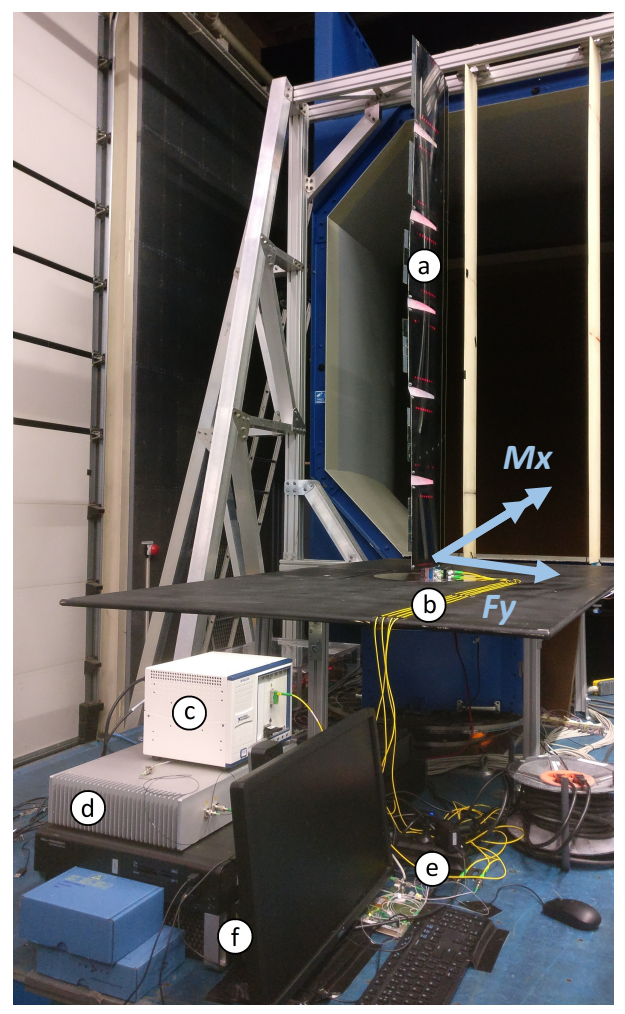

Figure 5. The experimental setup at the OJF (Open Jet Facility) low speed wind tunnel, showing the (a) wing, (b) optical fibers (yellow), (c) National Instruments interrogator, (d) Optics11 interrogator, (e) Thorlabs optical switch, and the (f) Data acquisition system.

\section{Experimental Setup}

The experiments for this study took place in the Open Jet Facility (OJF), a low speed wind tunnel at TU Delft's Aerospace Engineering faculty. Figure 5 shows the complete setup in the OJF, including the test specimen, the two optical fiber measurement systems, the optical switch, and the data acquisition system.

Figure 6 gives a brief overview of the experimental workflow. The controller provides an input command that brings about appropriate actuator movements in the modules. This causes a morphing sequence to occur and the actuator position feedback is recorded. Simultaneously, the deflection of the module is calculated and recorded through the output of the FBG and FBG Pair sensor measurements. Finally, the real morphing deformations are evaluated by comparison. 


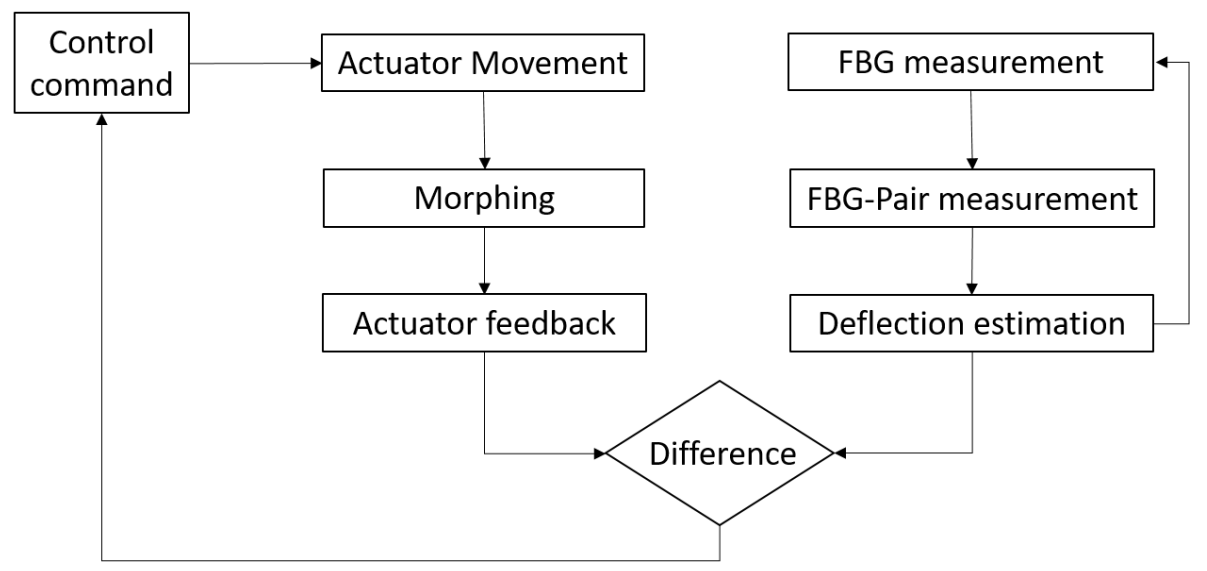

Figure 6. Block diagram depicting the sequential workflow of the experiment.

The test specimen is a carbon fiber composite morphing wing demonstrator manufactured as part of the SmartX project. The wing has a NACA 6510 profile, a span of $1800 \mathrm{~mm}$ and a chord of $500 \mathrm{~mm}$. It features 6 independent morphing trailing edge sections with optical fibers running through each of them. These sections are allowed to deflect up to $+30 /-20 \mathrm{~mm}$, whilst allowing a rotation of $40^{\circ}$ at the root of the trailing edge. The wing sits vertically on a root balance platform with the leading edge facing the incoming airflow.

Each of the optical fibers contained fiber Bragg grating (FBG) sensors at pre determined positions (more details in Section 3.2). A spectral FBG interrogator (National Instruments, PXIe-4844) with $4 \mathrm{pm}$ resolution, $4 \mathrm{pm}$ accuracy, $40 \mathrm{~dB}$ dynamic range, and a wavelength range from $1510 \mathrm{~nm}$ to $1590 \mathrm{~nm}$ measured the local strain at each of these FBGs. Secondly, an FBG-Pair interrogator (Optics11, ZonaSens) with 1 pm resolution, 1 pm accuracy, $160 \mathrm{~dB}$ dynamic range and a wavelength range from $1530 \mathrm{~nm}$ to $1560 \mathrm{~nm}$ measured the displacement between two given FBGs. In order to avoid vague readings due to both the systems interrogating the same fiber simultaneously, an optical switch (Thorlabs, OSW22-1310E) was used. All the fibers from the wing are connected to the measurement systems through the connector hub present at the wing root.

\subsection{Actuator Design}

Each of the 6 trailing edge modules have actuators at each end that control the morphing behavior. The concept of this morphing mechanism involves the upper surface of the module to be fixed and the lower surface to move with the help of actuators [44]. The actuators controlling the morphing movement are continuous torque servos (Volz DA 22-12-4112) designed for high continuous loads aimed for fixedwing applications. Figure 7 is a CAD render of the cross-section view of the module showing the internal setup and mechanism, including actuator, actuator arm, and the connections to the lower sliding surface. The upper surface of the module (Figure 8a) seamlessly connects to the wingbox, whilst the lower surface (Figure $8 \mathrm{~b}$ ) is left free, allowing it to slide in an out of a sliding surface/slot. The actuator arms are attached to this lower surface. Controlled activation of the individual actuators and, hence, the sliding motion of the lower surface subjects the module to bending and/or torsion. The actuator arm pulled towards the wingbox causes a negative deflection of the trailing edge, and vice versa. All the six morphing modules of the wing function in the same way. The measurements in this study pertain to module $\# 1$ and module \#6. These are the morphing modules at the wing root and tip, respectively (i.e., the bottom-most module and top-most modules in Figure 5). 


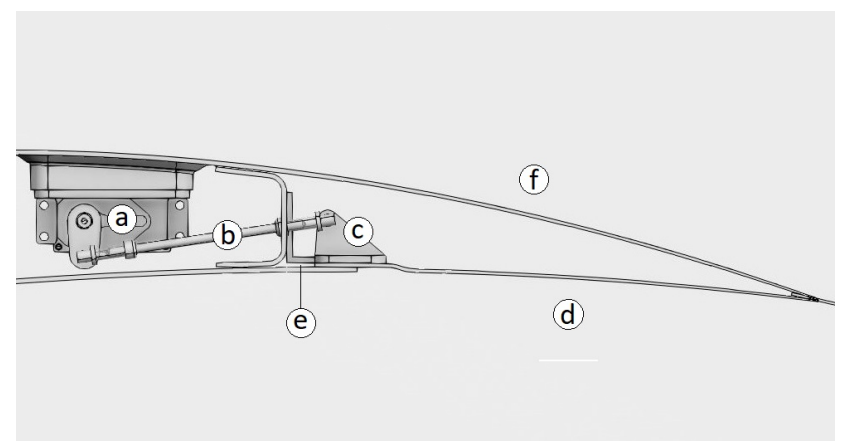

Figure 7. Cross-sectional view of the module showing the internal setup and morphing mechanism. This includes (a) the servo, (b) the servo arm, and (c) the pickup that, in turn, is connected to (d) the sliding lower surface. This lower surface moves in and out of (e) the slot. The fibers are bonded on the internal surface of (f) the upper surface of the module that seamlessly connects to the wingbox.

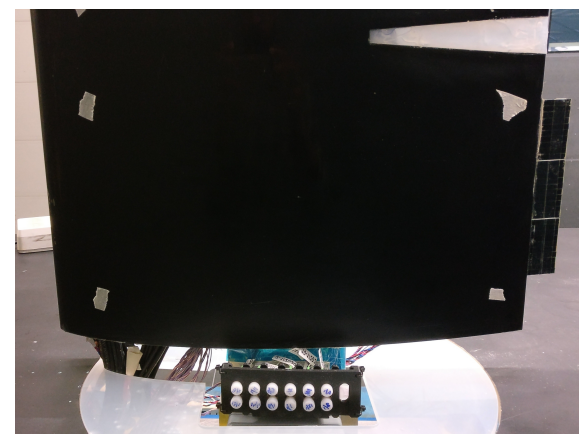

(a)

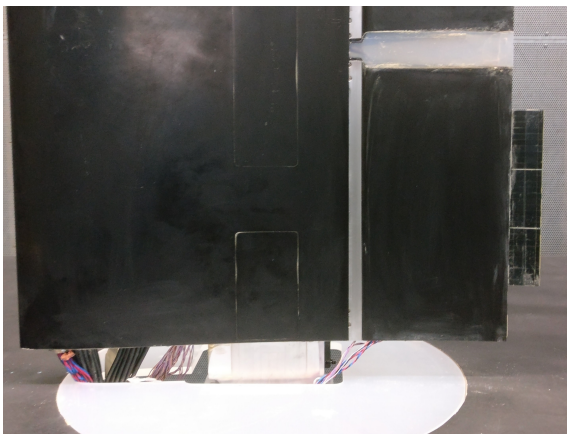

(b)

Figure 8. Zoomed-in images of module \#1 of the test wing showing the module's: (a) Upper surface (fixed) and (b) Lower surface (sliding). (a) The optical fiber connector hub at the bottom.

\subsection{Sensor Layout Design}

The layout of the optical fibers and the FBG sensor placement were followed based on an earlier study involving an aluminium morphing wing mockup [45]. An improved design was also incorporated in our previous work [33] involving a cantilever plate bending/torsion study. Figure 9 shows an illustration of the fiber layout (in red) and FBG location on the upper (inner) surface of the morphing modules. For better understanding, the illustration can be considered as a superimposition on Figure 8a. This configuration has a total of 4 FBG sensors, which are marked as S1 to S4 along the fiber.

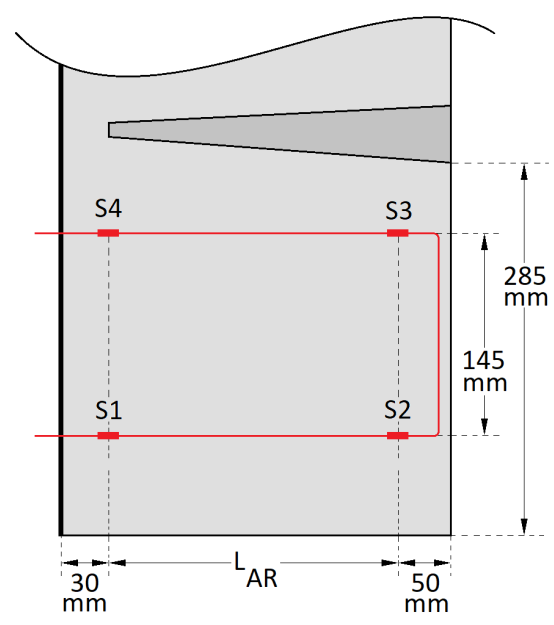

Figure 9. The U-shaped fiber layout (in red) on the upper (inner) surface of the morphing module. The location of FBG sensors (S1 to S4) along the fiber are as marked. 
The sensing fiber was bonded to the upper surface skin inside the wing. This was necessary so that the fiber does not disturb the air flow on the outside surface of the wing. Due to the ply dropping sequence [13], the inner surface had to be sanded to ensure the fibers were bonded on a flat surface. Cyanoacrylate adhesive (R\&G-Sekundenkleber Typ SF5) was used to bond the fiber in a U-shaped pattern. In this way, the gratings S1 and S4 were $30 \mathrm{~mm}$ from the wingbox, and gratings S2 and S3 $50 \mathrm{~mm}$ from the trailing edge. All the gratings were oriented parallel to the wing chord. The distance between grating pairs S1-S2 and S3-S4 is the effective sensing length $\left(L_{A R}\right)$. The distance between the S1-S2 and S3-S4 fibers was $145 \mathrm{~mm}$.

The measured local strain $\varepsilon$ from the FBG sensors is denoted by their corresponding sensor numbers as $\varepsilon_{1}$ to $\varepsilon_{4}$. The measured optical distance is given by $\Delta L_{1-2}$ and $\Delta L_{3-4}$ for grating pairs S1-S2 and S4-S3, respectively.

The optical fiber used was a standard single mode fiber (Corning ZBL SMF-28e) with an FC/APC connector. The properties of all the gratings in the fiber are mentioned in Table 1 and were manufactured by DK Photonics. The properties of the gratings were selectively defined to accommodate the capabilities of the both the optical interrogators used. The gratings were each $3 \mathrm{~mm}$ long and operated in the $1530 \mathrm{~nm}-1565 \mathrm{~nm}$ range (C-band). High reflection gratings were chosen $(>84 \%)$ with bandwidths greater than $0.85 \mathrm{~nm}$. The gratings had a temperature sensitivity of $10 \mathrm{pm} /{ }^{\circ} \mathrm{C}$.

Table 1. Properties of the grating sensors S1, S2, S3, and S4 (DK Photonics).

\begin{tabular}{ccccc}
\hline Property & S1 & S2 & S3 & S4 \\
\hline Wavelength (nm) & 1530.007 & 1540.016 & 1550.104 & 1559.992 \\
Bandwidth (nm) & 0.875 & 0.852 & 0.892 & 0.954 \\
Reflectivity (\%) & 86.29 & 84.61 & 84.15 & 89.11 \\
\hline
\end{tabular}

\section{Measurements}

The measurement process incorporated here relies on the initial calibration of the morphing module outside the wind tunnel and camber morphing and deflection tests inside the wind tunnel.

\subsection{Calibration}

The calibration tests were carried out beforehand for the modules in the aircraft hangar outside the wind tunnel. The test setup for the calibration was similar to the setup elaborated in Section 3 and in Figure 5. Additionally, a standard vernier scale was used for measuring the module deflections. The calibration was done for upward, downward, and twist morphing configurations for different actuator positions. The positive and negative deflections of the module were distinguished by their polarity and are identified at the interrogator level. These measurements formed baseline data to develop an experimentalbased-model that would later be used to estimate the deflections in the wind tunnel test. The algorithm depends on a transfer function that goes from measuring the strain output in the fiber due to the camber morphing to the trailing edge deflection. To achieve this, a relation between the raw FBG and FBGP data to the tip deflection is made.

\subsection{Camber Morphing -Wind Tunnel Test}

This procedure involves reading (both) the actuators and recording the strain and displacement data from the optical fiber system during morphing. The estimation is performed with the help of Maneuver Load Alleviation tests ((MLA); Section 4.3. The effectiveness of the system in monitoring the dynamic bending/twisting of the morphing module is determined for 3 test cases. This includes continuous dynamic movements of the module for a run of $80 \mathrm{~s}$ each. The module is deflected due to the input from the two actuators. A Transfer function that relates the tip deflection to the strain acquired from both 
the optical sensing methods is applied individually to both these actuators. This deflection is then correlated to the predicted servo angles.

The following was observed from the calibration and baseline measurement tests. In the event of pure upward (and downward) bending, $\varepsilon_{2}$ and $\varepsilon_{3} F B G$ readings and $\Delta L_{1-2}$ and $\triangle L_{3-4} F B G P$ readings alone were required to identify these changes. This brought us to a function of the form

$$
\delta_{c}=a \varepsilon_{2}+b \varepsilon_{3}+c \Delta L_{1-2}+d \Delta L_{3-4}+e,
$$

where $\delta_{c}$ is the deflection of the module measured at the center and $a, b, c, d$, and $e$ are constants.

On the other hand, when twist was considered, the measurements $\varepsilon_{1}$ and $\varepsilon_{4}$ that were not utilized in the bending case are involved and necessary to identify the twisting behavior. Having different functions for different (pre-known) morphing configurations is acceptable when static tests are considered where different test cases could be isolated and estimated. But, in case of a dynamic test (in the wind tunnel), a system that could involve and read all morphing cases was required.

This led to a preference to have separate transfer functions for both the actuators which could be applied for all morphing configurations simultaneously to have dynamic measurements. Additionally, this also gave the benefit to detect left and right tip deflections separately which could be related to the individual actuators at each end of the module. Therefore, combining all the sensor readings, the left tip deflection $\left(\delta_{l}\right)$ transfer function was defined as:

$$
\delta_{l}=f \varepsilon_{1}+g \varepsilon_{4}+h \Delta L_{1-2}+k,
$$

and the right tip deflection $\left(\delta_{r}\right)$ transfer function as:

$$
\delta_{r}=l \varepsilon_{1}+m \varepsilon_{4}+n \Delta L_{3-4}+o .
$$

\subsection{Maneuver Load Alleviation (MLA)}

To implement MLA for the SmartX-Alpha wing, the wing root shear forces and moments are measured by the OJF External Balance at $1000 \mathrm{~Hz}$ [41]. The core component of the Balance is a set of strain gauges, which can be attached to real-world operational aircraft wing structures. The measurements are filtered by second-order low-pass filters with a damping ratio 0.8 , and a circular frequency of $10 \mathrm{rad} / \mathrm{s}$. The number of servos $m=12$. The order of virtual shape functions are selected as $q=5$. The position limit of the servos equal $30 \mathrm{deg}$, whilst their rate limit equal $80 \mathrm{deg} / \mathrm{s}$. Regarding adjacent servos, if it is elastomer between them, then their relative motions are constrained within $10 \mathrm{deg}$. Otherwise, this value is relaxed to $55 \mathrm{deg}$. The servos are connected to a single RS-485 device, and their positions are fed back to the control computation in $66.7 \mathrm{~Hz}$ [41] The transport delay is approximately $15 \mathrm{~ms}$. The system identification results show that the servo dynamics can be modeled by second-order low-pass filters with damping ratio 0.71 and circular frequency $16.52 \mathrm{rad} / \mathrm{s}$. The control gain matrix in Equation (8) is chosen as $K=\operatorname{diag}\{0.1,0.1\}$. The parameters in Equation (13) are: $\sigma=0.001, \boldsymbol{W}_{1}=\boldsymbol{I}_{2 \times 2}$, and $W_{2}=I_{12 \times 12}$.

\section{Results}

Following the procedure explained in Section 4, experiments were performed on the SmartX morphing wing modules involving varying load indicators $F_{y}$ and $M_{x}$ with the intention of alleviating gust and maneuver loads. Significant movements of the modules due to the morphing sequences were detected using the strain and displacement outputs of the fiber sensors. Figures 10-12 show the servo positions compared with the estimated positions from the FOS (Fiber Optic Sensor) measurements for module \#1. Likewise, Figures 13-15 for module \#6. The positive and negative servo angles suggest that the surface of the module morphs downwards to increase lift and upwards to decrease lift, respectively (refer to Section 2.2.3). 


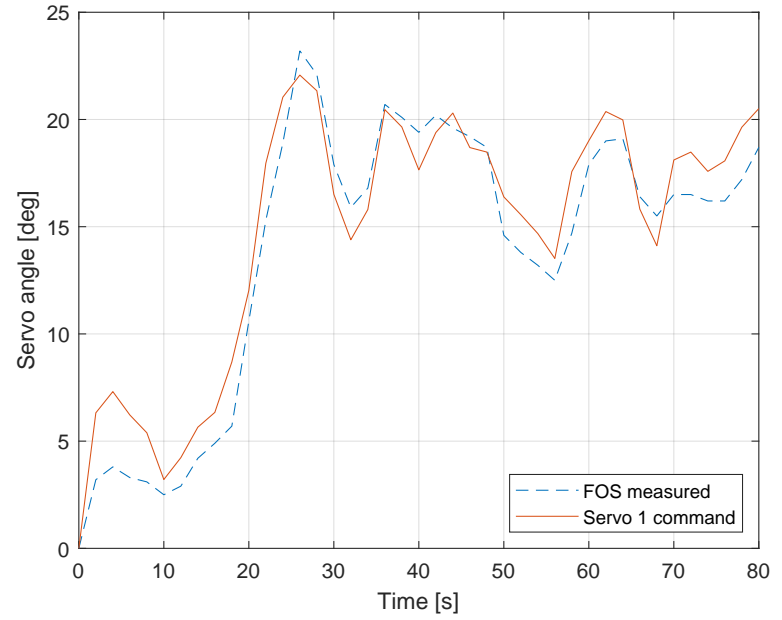

(a)

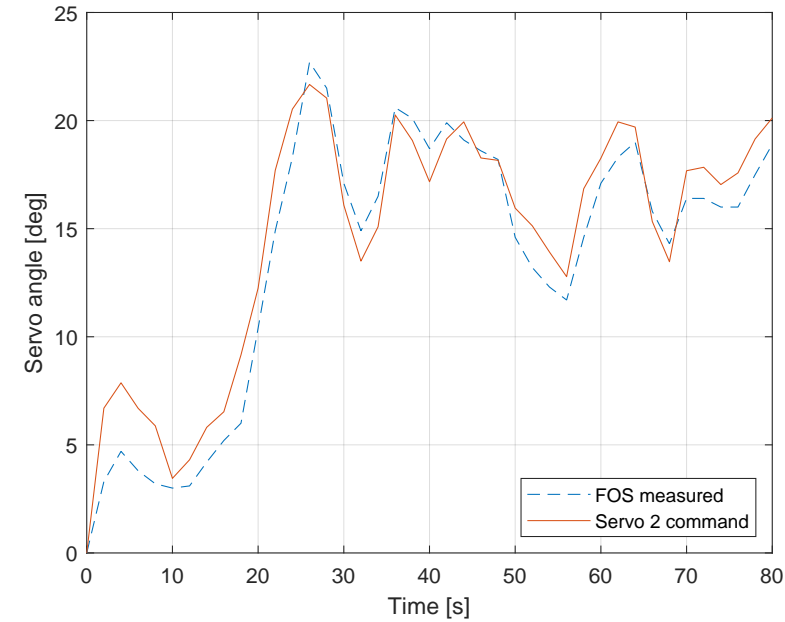

(b)

Figure 10. Estimated position with respect to module \#1 deflections for the $F_{y}=20$ and $M_{x}=0$ case. The positions of actuators 1 and 2 are separated and shown in $(\mathbf{a}, \mathbf{b})$, respectively.

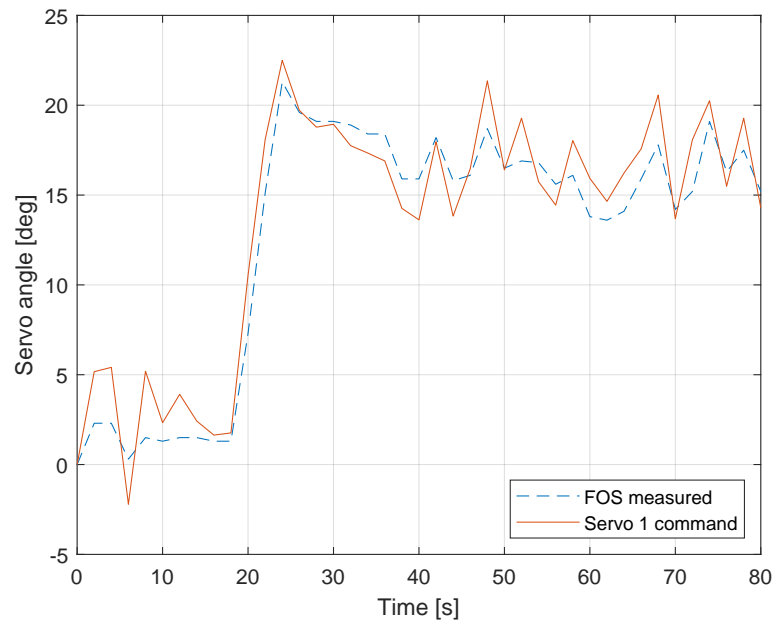

(a)

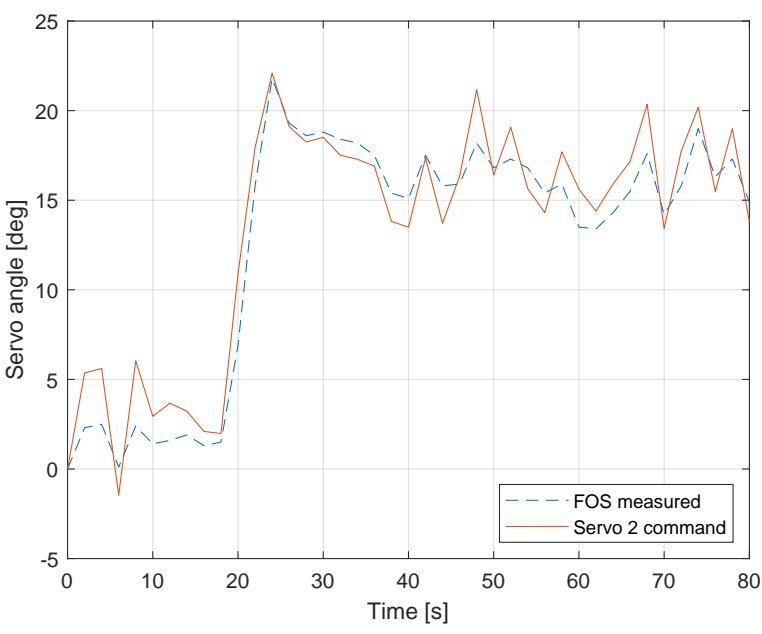

(b)

Figure 11. Estimated position with respect to module \#1 deflections for the $F_{y}=25$ and $M_{x}=0$ case. The positions of actuators 1 and 2 are separated and shown in $(\mathbf{a}, \mathbf{b})$, respectively.

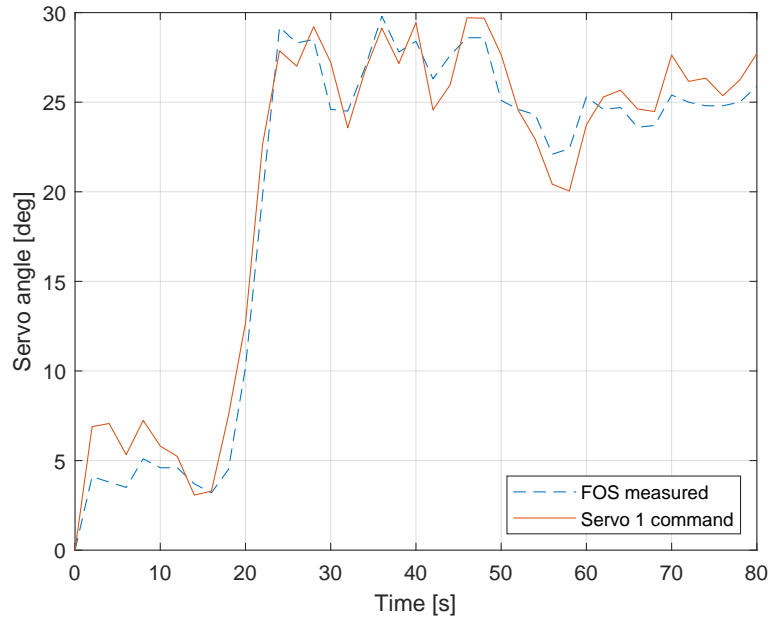

(a)

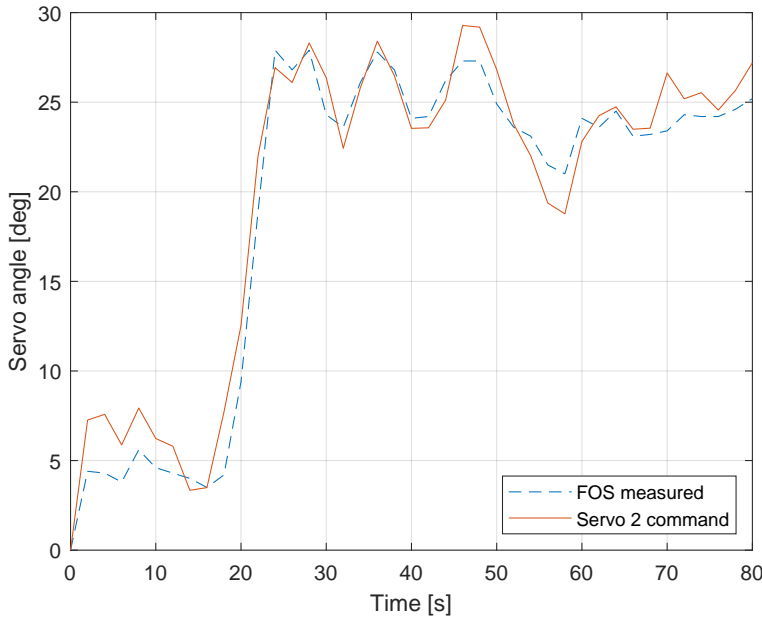

(b)

Figure 12. Estimated position with respect to module \#1 deflections for the $F_{y}=30$ and $M_{x}=0$ case. The positions of actuators 1 and 2 are separated and shown in $(\mathbf{a}, \mathbf{b})$, respectively. 


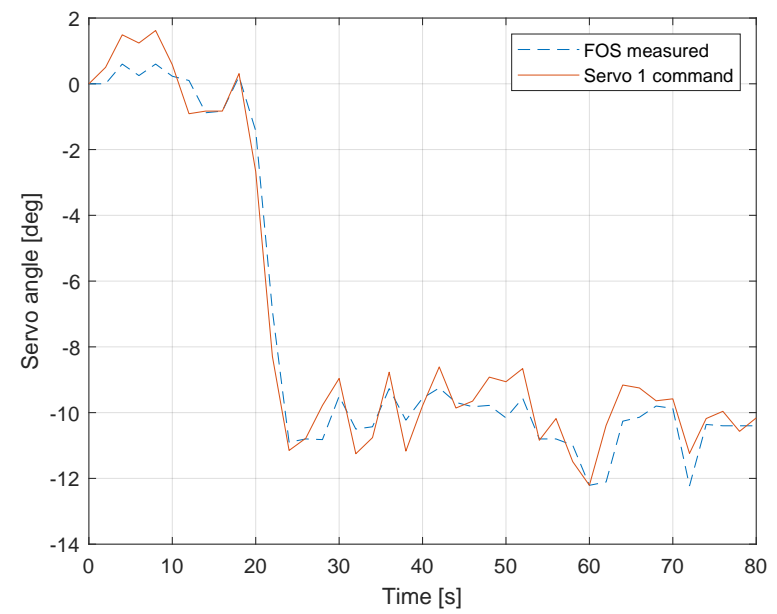

(a)

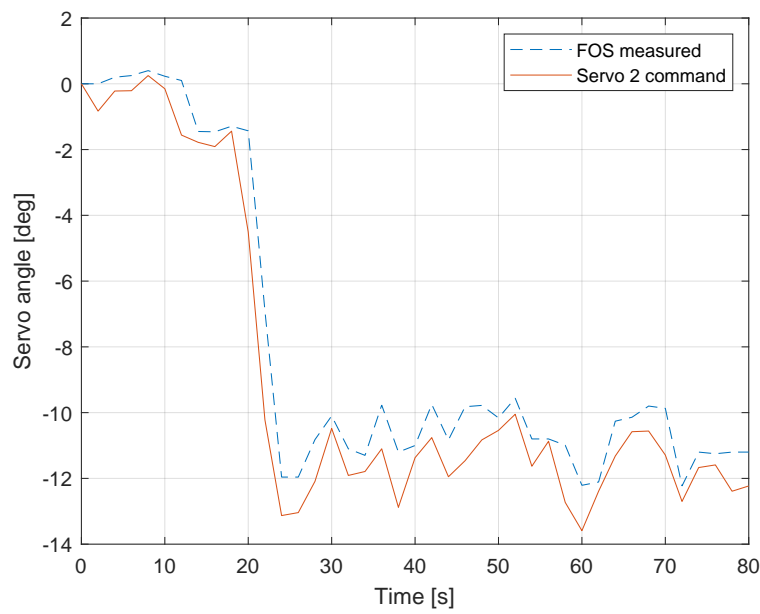

(b)

Figure 13. Estimated position with respect to module \#6 deflections for the $F_{y}=20$ and $M_{x}=0$ case. The positions of actuators 1 and 2 are separated and shown in $(\mathbf{a}, \mathbf{b})$, respectively.

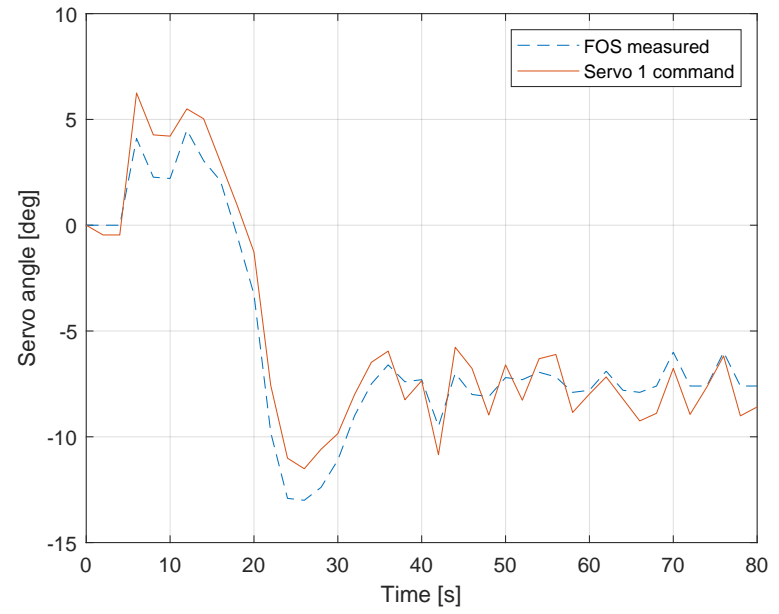

(a)

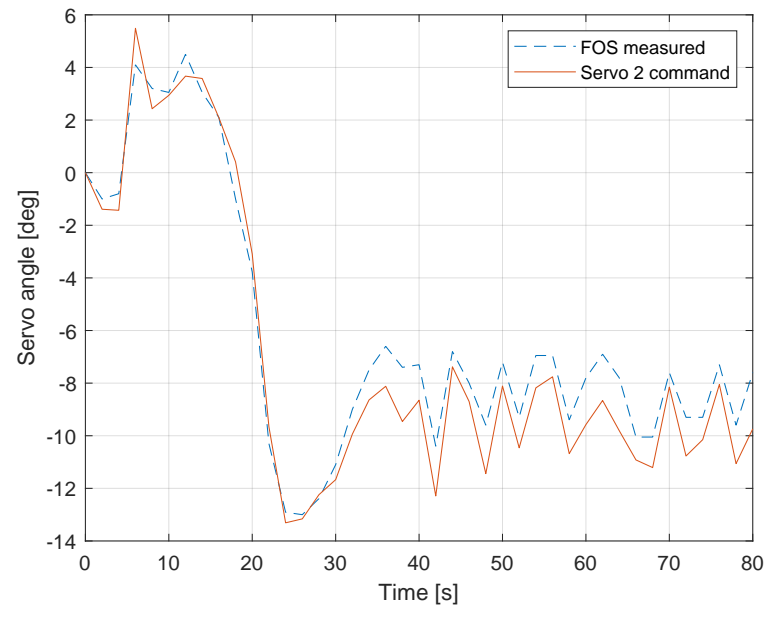

(b)

Figure 14. Estimatedposition with respect to module \#6 deflections for the $F_{y}=25$ and $M_{x}=0$ case. The positions of actuators 1 and 2 are separated and shown in $(\mathbf{a}, \mathbf{b})$, respectively.

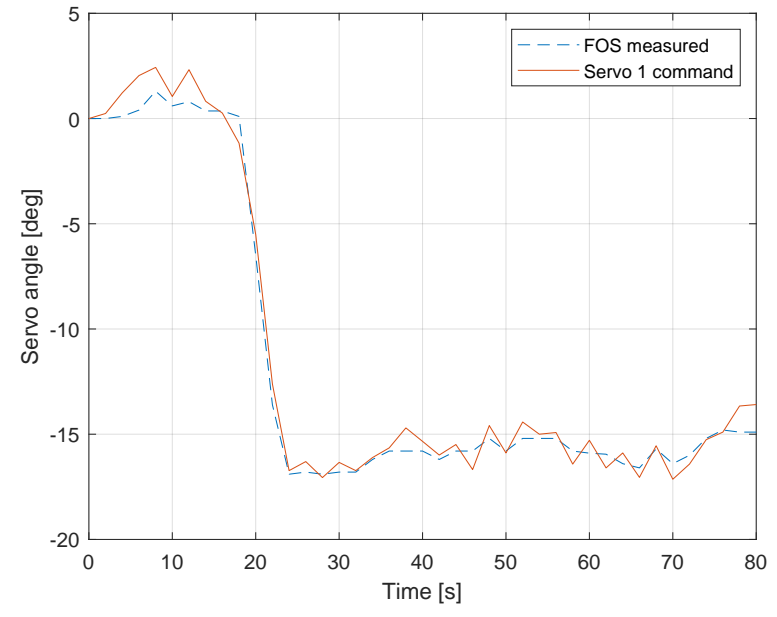

(a)

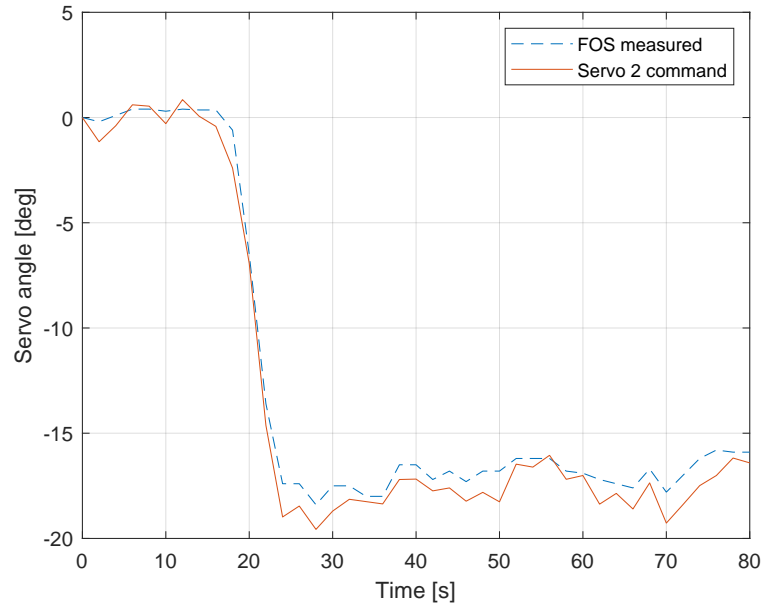

(b)

Figure 15. Estimated position with respect to module \#6 deflections for the $F_{y}=30$ and $M_{x}=0$ case. The positions of actuators 1 and 2 are separated and shown in $(\mathbf{a}, \mathbf{b})$, respectively. 


\section{Discussions}

This research demonstrates the working of a multi-modal optical fiber-based sensing method to predict the position of a wing camber morphing module in the wind tunnel. The effectiveness of the proposed sensing method in monitoring the morphing sequence is determined for three different Maneuver Load Alleviation (MLA) cases. These morphing sequences include: pure upward bending, pure downward bending, pure twist, and combined twist and bending. The morphing sequences are brought about by two servos at each end of the morphing module.

A single core single-mode fiber containing four fiber Bragg gratings (FBG) was bonded to the module. Local strain measurements from each FBG and displacement measurements from each FBG pair were measured for each test. FBGs are known to be temperature sensitive. As the sensitivity within the wind tunnel was measured to be small enough (within $\pm 0.5^{\circ}$ ), the temperature component was neglected in the final calculation.

A lucid explanation of the experimental measurement strategy is as follows. An appropriate servo command brings about a certain morphing sequence which results in a change in shape of the module. This change is picked up as strain by the FBG sensors and FBG sensor pairs in the bonded optical fibers. The algorithm then calculates the deflection of the module by estimating the position of the actuators using the baseline measurements as reference. This is done separately for each actuator to account for bending and/or twisting. It is to be noted that, due to hardware limitations, a truly real-time measurement was not achieved. Although important, this did not have an effect on the study as the prime requirement was to demonstrate the working of the principle and its application on a morphing wing in the wind tunnel.

Overall, the estimation coincides and follows the trend for all the six cases (Figures 10-15). Initially until $\sim 15 \mathrm{~s}$ the module is left free, and no servo commands are given. The morphing sequence starts thereafter. The mismatch is seen to be within $3 \mathrm{~mm}$ for the position estimation. This mismatch is better depicted through Figure 16, where the diagonal line represents a 1:1 estimation in degrees between the servo commands and the FOS measurements. The points are seen to be scattered within $+3^{\circ}$ to $-3^{\circ}$ from this diagonal. Additionally, since the movement range of the module is mostly from $13^{\circ}$ to $30^{\circ}$, there are few measurement points below $13^{\circ}$.

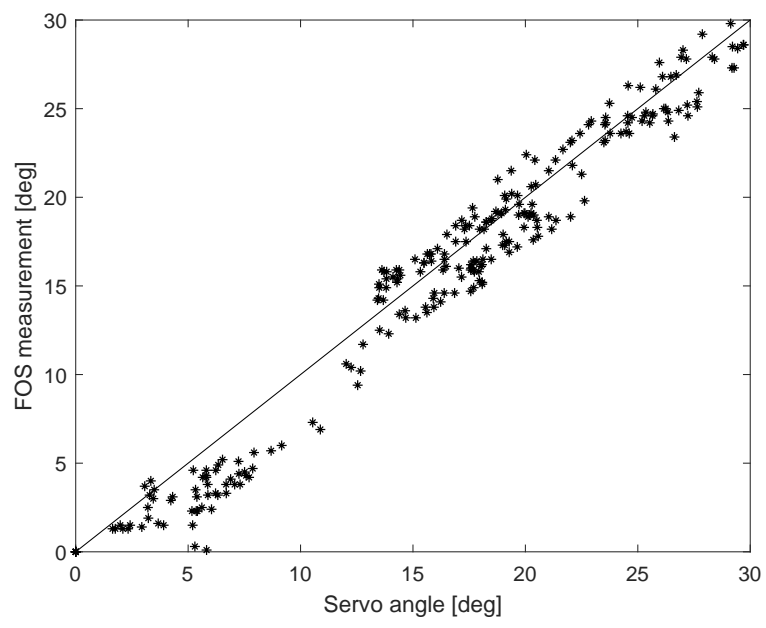

Figure 16. The mismatch in estimation between the servo command and the fiber optic sensor (FOS) measurement in degrees.

When the servo angle variations are small, there is very little morphing taking place. This is more prominent when the servo changes directions throughout the test run. This effect is noticed in Figure 11a,b, starting from the $40 \mathrm{~s}$ mark, and more prominently throughout Figure 15a,b. 
The inaccuracies in the fibers/sensors, experimental setup and possible error sources that may directly or indirectly affect the measurements are discussed as follows. There are mainly three aspects that could lead to the mismatches between the servo angles and fiber sensed data: (1) servo dynamics and delays; (2) random error from measurements and calculation; (3) nonlinear mechanism backlash.

Regarding the first point, the servo command given by the control computer cannot be immediately executed by the servo. Experimental data shows there is an approximately $15 \mathrm{~ms}$ of transport delay, which is sufficiently small when compared to the data rate of the optical interrogators. Moreover, the Volz DA 22-12-4112 servo used by the SmartX-Alpha has a transfer function as $H(s)=\frac{\omega^{2}}{s^{2}+2 \zeta \omega s+\omega^{2}}$, where $s$ is the Laplace variable, $\zeta=0.71$, $\omega=16.52 \mathrm{rad} / \mathrm{s}$. This further causes a frequency-dependent phase lag between the commanded and real servo angle.

The second, unpredictable change in the measured value, comes from the random error in the measurement. The random error in the experiment is significant as compared to the offset and/or scale factor errors. This is because an initial calibration procedure was done that removes the systematic errors. To account for the random errors, the error was quantified experimentally based on static deflection tests for different morphing sequences. The measured standard deviation for the quantities $\varepsilon_{1}$ and $\varepsilon_{4}$ was $<0.05$, and, for $\Delta L_{1-2}$ and $\Delta L_{3-4}$, was $<0.1$. This measurement accuracy caused a variation of $\pm 1 \mathrm{~mm}$ in the transfer functions $\delta_{l}$ and $\delta_{r}$.

Last but not least, the mismatches are contributed by the nonlinear backlash in the morphing mechanisms. Backlash is a clearance phenomenon in mechanical systems caused by gaps between the parts. The present SmartX-Alpha wing involves largely handcrafted structural components and manual laminate layup, which inevitably lead to manufacturing imperfections, including the tolerance between the bottom skin and the sliding interface. As a result, whenever the servo command changes directions, the pick-up point needs to rotate, and the bottom skin needs to bend, before the ideal translational sliding actually happens [41]. This nonlinear backlash phenomenon has caused hysteresis effects in both the OJF external balance and the optical fiber measurements.

In Figure 17, the servos start from $30 \mathrm{deg}$ and gradually reduce to $-30 \mathrm{deg}$, and then increase back to $30 \mathrm{deg}$. It can be observed that owing to backlash, the same servo command leads to different wing root shear forces $\left(F_{y}\right)$ in upstroke and downstroke. Experimental data show the backlash servo angle is approximately in the range of $-2.5 \mathrm{deg}$ to $2.5 \mathrm{deg}$. Backlash is one of the predominant inducements for the estimation errors.

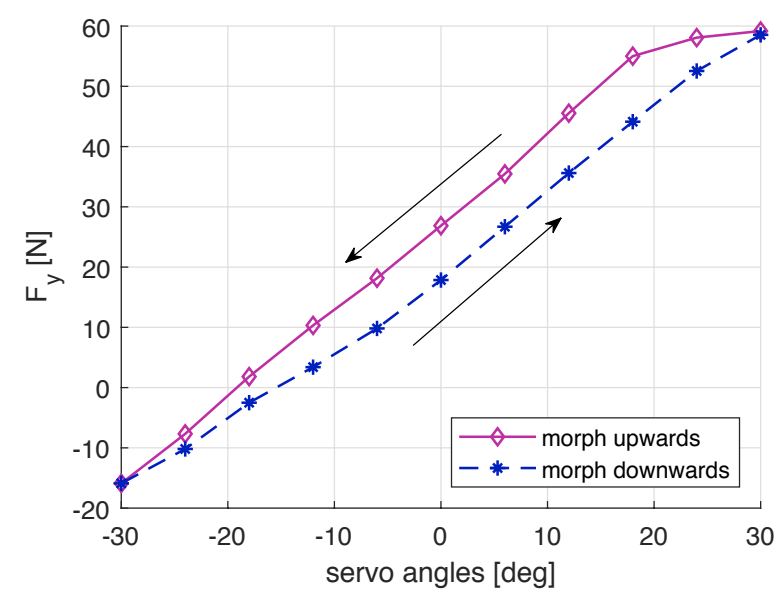

Figure 17. Experimental result for backlash-induced wing root shear force hysteresis loop.

\section{Conclusions}

This research presents the principles, design, and, finally, the application of a novel optical sensing method for measuring the camber morphing behavior of a wing module. 
The study proposed here extends the two-dimensional idealization of a wing flap through a cantilever plate [33] and a morphing wing mockup study [45]. The ability of this method to estimate the deflections of the morphing module when subjected to a bending and/or twist proves its potential for shape monitoring of morphing structures.

This work successfully demonstrates the capability of a hybrid sensing principle that involves a combination of fiber Bragg grating (FBG) and fiber Bragg grating pair (FBGP) sensing for wing deflection estimation. This work also shows that the deflection estimation can be easily achieved by using just four FBG sensors in a single fiber. The sources of inaccuracies and errors are identified, and the estimated measurements are found to have within $10 \%$ error for trailing edge deflection estimation.

Having a higher interrogator sampling rate and a faster switch rate between the two optical interrogators would result in higher accuracy and allow better real-time sensing. This method could be extended to all the 6 morphing modules of the SmartX-Alpha wing, interconnected using a NxM matrix optical switch to get real-time feedback of the entire wing. Additionally, the spanwise deflections of the wing can also be captured by incorporating and extending the work on a beam structure [40] using the same approach These steps are reserved for future work.

Author Contributions: Conceptualization, N.N., X.W., and R.M.G.; methodology, N.N. and X.W.; software, N.N. and X.W.; validation, N.N. and X.W.; formal analysis, N.N. and X.W.; investigation, N.N., X.W., and R.M.G.; resources, R.M.G.; data curation, N.N. and X.W.; writing-original draft preparation, N.N. and X.W.; writing - review and editing, N.N., X.W., and R.M.G.; visualization, N.N. and X.W.; supervision, R.M.G.; project administration, R.M.G.; funding acquisition, R.M.G. All authors have read and agreed to the published version of the manuscript.

Funding: This work is part of the strategic project SmartX in the Aerospace Structures and Materials department, Faculty of Aerospace Engineering, Delft University of Technology. The SmartX project is focused on the design and development of smart wing technology.

Institutional Review Board Statement: Not applicable.

Informed Consent Statement: Not applicable.

Data Availability Statement: The data presented in this study are openly available in 4TU. Research Data at 10.4121/14623056.

Acknowledgments: The authors would like to express their special thanks to T. Mkhoyan. Moreover, thanks are given to the SmartX-Alpha contributors V. Stuber, I. Mkhoyan, and N. Thakrar. Furthermore, to the supervisors R. De Breuker, S. van der Zwaag, and J. Sodja. In memory of W.A. Groen.

Conflicts of Interest: The authors declare no conflict of interest.

\section{References}

1. Boller, C. Structural Health Monitoring-An Introduction and Definitions; Wiley: New York, NY, USA, 2009.

2. Worden, K.; Dulieu-Barton, J. An Overview of Intelligent Fault Detection in Systems and Structures. Struct. Health Monit. 2004, 3, 85-98. [CrossRef]

3. Giurgiutiu, V. Structural Health Monitoring of Aerospace Composites; Academic Press: New York, NY, USA, 2015.

4. Groves, R.M. Inspection and Monitoring of Composite Aircraft Structures. In Reference Module in Materials Science and Materials Engineering; Elsevier: Oxford, UK, 2017. [CrossRef]

5. Goossens, S.; De Pauw, B.; Geernaert, T.; Salmanpour, M.S.; Sharif Khodaei, Z.; Karachalios, E.; Saenz-Castillo, D.; Thienpont, H.; Berghmans, F. Aerospace-grade surface mounted optical fibre strain sensor for structural health monitoring on composite structures evaluated against in-flight conditions. Smart Mater. Struct. 2019, 28, 065008. [CrossRef]

6. Iele, A.; Leone, M.; Consales, M.; Persiano, G.; Brindisi, A.; Ameduri, S.; Concilio, A.; Ciminello, M.; Apicella, A.; Bocchetto, F.; et al. Load monitoring of aircraft landing gears using fiber optic sensors. Sens. Actuators A Phys. 2018, $281,31-41$. [CrossRef]

7. Cooperman, A.; Martinez, M. Load monitoring for active control of wind turbines. Renew. Sustain. Energy Rev. 2014, 41, 189-201. [CrossRef]

8. Feng, X.; Han, Y.; Wang, Z.; Liu, H. Structural performance monitoring of buried pipelines using distributed fiber optic sensors. J. Civ. Struct. Health Monit. 2018, 8, 509-516. [CrossRef] 
9. Li, H.N.; Ren, L.; Jia, Z.G.; Yi, T.H.; Li, D.S. State-of-the-art in structural health monitoring of large and complex civil infrastructures. J. Civ. Struct. Health Monit. 2016, 6, 3-16. [CrossRef]

10. De Breuker, R.; Abdalla, M.M.; Gürdal, Z. A Generic Morphing Wing Analysis and Design Framework. J. Intell. Mater. Syst. Struct. 2011, 22, 1025-1039. [CrossRef]

11. Boller, C. Structural Health Monitoring-Its Association and Use. In New Trends in Structural Health Monitoring; Ostachowicz, W., Güemes, J.A., Eds.; Springer: Vienna, Austria, 2013; pp. 1-79.

12. Li, D.; Zhao, S.; Da Ronch, A.; Xiang, J.; Drofelnik, J.; Li, Y.; Zhang, L.; Wu, Y.; Kintscher, M.; Monner, H.P.; et al. A review of modelling and analysis of morphing wings. Prog. Aerosp. Sci. 2018, 100, 46-62. [CrossRef]

13. Mkhoyan, T.; Thakrar, R.N.; De Breuker, R.; Sodja, J. Design of a Smart Morphing Wing Using Integrated and Distributed Trailing-Edge Camber Morphing. In Proceedings of the ASME 2020 Conference on Smart Materials, Adaptive Structures and Intelligent Systems, Online, 15 September 2020.

14. Virgilio Pereira, M.D.; Kolmanovsky, I.; Cesnik, C.E.; Vetrano, F. Model Predictive Control Architectures for Maneuver Load Alleviation in Very Flexible Aircraft. In AIAA Scitech 2019 Forum; Number January; American Institute of Aeronautics and Astronautics: San Diego, CA, USA, 2019. [CrossRef]

15. Ferrier, Y.; Nguyen, N.T.; Ting, E.; Chaparro, D.; Wang, X.; de Visser, C.C.; Chu, Q.P. Active Gust Load Alleviation of High-Aspect Ratio Flexible Wing Aircraft. In Proceedings of the 2018 AIAA Guidance, Navigation, and Control Conference, Kissimmee, FL, USA, 8-12 January 2018; American Institute of Aeronautics and Astronautics: Kissimmee, FL, USA, 2018; pp. 1-36. [CrossRef]

16. de FV Pereira, M.; Kolmanovsky, I.; Cesnik, C.E.S.; Vetrano, F. Model Predictive Control for Maneuver Load Alleviation in Flexible Airliners. In Proceedings of the International Forum on Aeroelasticity and Structural Dynamics (IFASD 2019), Savannah, GA, USA, 9-13 June 2019; Volume 16, pp. 420-432.

17. Bi, Y.; Xie, C.; An, C.; Yang, C. Gust load alleviation wind tunnel tests of a large-aspect-ratio flexible wing with piezoelectric control. Chin. J. Aeronaut. 2016. [CrossRef]

18. Rugh, W.J. Analytical framework for gain scheduling. IEEE Control Syst. Mag. 1991, 11, 79-84. [CrossRef]

19. Wang, X.; van Kampen, E.; Chu, Q.; Lu, P. Stability Analysis for Incremental Nonlinear Dynamic Inversion Control. J. Guid. Control Dyn. 2019, 42, 1116-1129. [CrossRef]

20. Wang, X.; van Kampen, E.; Chu, Q.P.; De Breuker, R. Flexible Aircraft Gust Load Alleviation with Incremental Nonlinear Dynamic Inversion. J. Guid. Control Dyn. 2019, 42, 1519-1536. [CrossRef]

21. Ma, Z.; Chen, X. Fiber Bragg Gratings Sensors for Aircraft Wing Shape Measurement: Recent Applications and Technical Analysis. Sensors 2018, 19, 55. [CrossRef]

22. Udd, E.; Spillman, W. Fiber Optic Sensors: An Introduction for Engineers and Scientists, 2nd ed.; Wiley: New York, NY, USA, 2011.

23. Ramakrishnan, M.; Rajan, G.; Semenova, Y.; Farrell, G. Overview of Fiber Optic Sensor Technologies for Strain/Temperature Sensing Applications in Composite Materials. Sensors 2016, 16, 99. [CrossRef]

24. Floris, I.; Adam, J.M.; Calderón, P.A.; Sales, S. Fiber Optic Shape Sensors: A comprehensive review. Opt. Lasers Eng. 2021, 139, 106508. [CrossRef]

25. Wada, D.; Igawa, H.; Tamayama, M.; Kasai, T.; Arizono, H.; Murayama, H. Flight demonstration of aircraft wing monitoring using optical fiber distributed sensing system. Smart Mater. Struct. 2019, 28. [CrossRef]

26. Li, H.; Zhu, L.; Sun, G.; Dong, M.; Qiao, J. Deflection monitoring of thin-walled wing spar subjected to bending load using multi-element FBG sensors. Optik 2018, 164, 691-700. [CrossRef]

27. Mizutani, Y.; Groves, R.M. Multi-Functional Measurement Using a Single FBG Sensor. Exp. Mech. 2011, 51, 1489-1498. [CrossRef]

28. Nicolas, M.J.; Sullivan, R.W.; Richards, W.L. Large Scale Applications Using FBG Sensors: Determination of In-Flight Loads and Shape of a Composite Aircraft Wing. Aerospace 2016, 3, 18. [CrossRef]

29. Gander, M.; Macpherson, W.; Mcbride, R.; Jones, J.; Zhang, L.; Bennion, I.; Blanchard, P.; Burnett, J.; Greenaway, A. Bend measurement using Bragg gratings in multicore fibre. Electron. Lett. 2000, 36, 120-121. [CrossRef]

30. Flockhart, G.M.H.; MacPherson, W.N.; Barton, J.S.; Jones, J.D.C.; Zhang, L.; Bennion, I. Two-axis bend measurement with Bragg gratings in multicore optical fiber. Opt. Lett. 2003, 28, 387-389. [CrossRef]

31. Westbrook, P.S.; Kremp, T.; Feder, K.S.; Ko, W.; Monberg, E.M.; Wu, H.; Simoff, D.A.; Taunay, T.F.; Ortiz, R.M. Continuous Multicore Optical Fiber Grating Arrays for Distributed Sensing Applications. J. Light. Technol. 2017, 35, 1248-1252. [CrossRef]

32. Jutte, C.V.; Ko, W.L.; Stephens, C.A.; Bakalyar, J.A.; Richards, W.L.; Parker, A.R. Deformed Shape Calculation of a Full-Scale Wing Using Fiber Optic Strain Data from a Ground Loads Test; NASA Technical Reports Server, NASA/TP—2011-215975; NASA: Greenbelt, MD, USA, 2011.

33. Nazeer, N.; Groves, R.M. Load Monitoring of a Cantilever Plate by a Novel Multi-modal Fibre Optic Sensing Configuration. SN Appl. Sci. 2021, in press.

34. Kashyap, R. Chapter Innovation and Intellectual Property Rights. In Fabrication of Bragg Gratings; Academic Press: Boston, UK, 2010; Chapter 3, pp. 53-118.

35. Hill, K.O.; Meltz, G. Fiber Bragg grating technology fundamentals and overview. J. Light. Technol. 1997, 15, 1263-1276. [CrossRef]

36. Kersey, A.D.; Davis, M.A.; Patrick, H.J.; LeBlanc, M.; Koo, K.P.; Askins, C.G.; Putnam, M.A.; Friebele, E.J. Fiber grating sensors. J. Light. Technol. 1997, 15, 1442-1463. [CrossRef]

37. James, S.; Tatam, R. Optical fibre long-period grating sensors: Characteristics and application. Meas. Sci. Technol. 2003, 14, 49-61. [CrossRef] 
38. Kersey, A.D. A Review of Recent Developments in Fiber Optic Sensor Technology. Opt. Fiber Technol. 1996, 2, 291-317. [CrossRef]

39. Gruca, G.; Rijnveld, N. Optical Fiber-Based Sensor System. GB Patent Application No. 3335014, 20 June 2018.

40. Nazeer, N.; Groves, R.M.; Benedictus, R. Simultaneous Position and Displacement Sensing Using Two Fibre Bragg Grating Sensors. In Proceedings of the SPIE Smart Structures + Nondestructive Evaluation, Denver, CO, USA, 3-7 March 2019. [CrossRef]

41. Wang, X.; Mkhoyan, T.; Mkhoyan, I.; De Breuker, R. Seamless Active Morphing Wing Simultaneous Gust and Maneuver Load Alleviations. arXiv 2020, arXiv:2012.14520.

42. Isidori, A. Nonlinear Control Systems, 3rd ed.; Springer: Berlin, Germany, 1995; pp. 257-291.

43. Khalil, H.K. Nonlinear Systems; Prentice-Hall: Upper Saddle River, NJ, USA, 2002.

44. Werter, N.; Sodja, J.; Spirlet, G.; De Breuker, R. Design and Experiments of a Warp Induced Camber and Twist Morphing Leading and Trailing Edge Device. In Proceedings of the 24th AIAA/AHS Adaptive Structures Conference, San Diego, CA, USA, 4-8 January 2016.

45. Nazeer, N.; Groves, R.M. Shape Sensing of a Morphing Trailing Edge Section Using Four Fibre Bragg Grating Sensor Pairs. 2021, Manuscript submitted for publication. 